\title{
ANNOTATION
}

\section{The Journal in 1940}

When the War came last year it was obvious that some curtailment in the size of the monthly numbers would have to be made, since the management could not foretell the financial position with any exactitude.

It is now possible to state that we shall be able to continue regular publication at any rate for this year, and every effort will be made to continue for the "duration." But the rationing system must continue, although it will be our aim to make this ration as large as possible. Papers dealing with war conditions will have priority over more ordinary material.

In these circumstances some delay in publishing papers is inevitable. We hope authors will bear this in mind and the Editors on their side will do their best to avoid undue delay.

Authors can help the Journal materially by keeping their proof corrections as low as possible. Manifest errors must of course be corrected, but there is no need to make endless corrections in the interests of the English language. The Editors feel that they can almost pardon a split infinitive in the cause of economy. And the writer has always had a sneaking sort of partiality for that old Kaiser Sigismund, who at the Council of Constance in 1414, was pulled up by one of the Cardinals on an obvious slip in grammar and replied "I am King of the Romans and super grammaticam." It is so easy to make mistakes not only in professional matters but also in writing and speaking.

\section{ABSTRACTS}

\section{MISCELLANEOUS}

(1) Cecchetto (Verona).--Paracentesis of the anterior chamber in the treatment of various ocular diseases. (La paracentesi della camera anteriore nelle piu svariate malattie oculari). Rass. Ital. d'Ottal., January-February, 1939.

(1) The value of this remedy, which goes back to Galen, is insufficiently recognised, says Cecchetto; it is of great use in many ocular conditions. The changes in the eye after paracentesis have been studied by several authors, both those after a single operation and those which follow repeated paracentesis. There is little doubt that the aqueous is formed by the ciliary body; Greeff 
noted that after the anterior chamber is emptied, bullae form all over the ciliary region; the epithelium of the ciliary processes is raised into bullae visible to small magnification, and containing masses of coagulated material. The bullae burst and the contents are thrown into the aqueous. This is seen within a few minutes of the paracentesis. Other observers have repeated the paracentesis daily for a number of months, and find that the ciliary body is more developed than that of the control eye. The iris also, is thickened to three times its normal ; this seems due to an increase of the connective tissue; there was an increase in the number of vessels of the iris; from these changes it may be gathered that repeated paracentesis increases the activity of the metabolism of the iris and ciliary body and causes hypertrophy of the stroma and the vessel walls. It is easy to see how the eye may benefit from the increased activity.

The author uses paracentesis not only in chronic and infantile glaucoma-in which conditions he claims great gain from its employment-but also in many conditions where the uveal tract seems to be working insufficiently. In a number of cases of high myopia with macular change and vitreous floaters, he has found it helpful. In most of these cases other remedies also were applied and therefore it remains in doubt how much is to be ascribed to the operations. The author has had good results in retinitis pigmentosa and promises to give these in a later paper.

\section{HaROLd GRIMSDALE.}

(2) Borsotti (Geneva).- The importance of over-action of the inferior oblique in the surgical treatment of paralysis of the superior oblique. (L'importaza del riconoscimento della iperfunzione del piccolo obliquo nel trattamento chirurgico delle paralisi del grande obliquo). Rass. Ital. d'Ottal., MarchApril, 1939.

(2) This paper is a corollary to that recently appearing in the Ann. d'Ottal. In it Borsotti re-states the difficulties in diagnosis of loss of power of a vertical motor muscle; he points out that the probability of injury to the superior oblique is much greater than that of injury to a single rectus muscle, since the former is supplied by a nerve which has no other muscle to supply, while the recti are a group supplied by one nerve. He passes shortly over the methods which have been proposed for the relief of the symptoms and decides that no operation is so successful in removing them as weakening the inferior oblique when there is manifest over-action of this muscle. He shows how careful examination of the diplopia and especially of the cyclophoria will show this over-action, and gives account of cases in which myectomy of the inferior oblique gave relief. The operation is conducted as follows: after subcutaneous injection of the anaesthetic, an incision is made along the 
inner half of the inferior orbital border. The middle of this incision should be a line dropped vertically from the supraorbital notch. The skin and subjacent orbicularis are separated down to the periosteum, then by means of squint hook the tendon and muscle of the oblique is picked up; a portion some 7 to $10 \mathrm{~mm}$. wide is excised from the belly of the muscle.

In the cases in which over-action of the inferior oblique was definite, the operation was followed by great relief ; in most cases the troublesome cyclophoria is corrected ; it is true that recession of the inferior rectus of the opposite side would seem theoretically to be the best method of correction, but this takes no account of the over-action of the inferior oblique, which almost constantly accompanies paresis of the superior. In this paper, as in the former, he gives as an appendix, Franceschetti's chart for the diagnosis of paresis and over-action of the various vertically moving muscles.

HAROLD GRIMSDALE.

(3) Agnello (Addis Ababa).-Toxic amblyopia from filix mas. (Amaurosi tossica da felce maschio). Rass. Ital. d'Ottal., March-April, 1939.

(3) The use of filix mas as a vermifuge is attended with risk of toxic amblyopia especially if the drug be allowed to remain for any length of time in the bowels; in the case recorded by Agnello the patient had passed a large worm, and was then given a large dose of filix mas; in a few hours he became comatose and on recovering consciousness, found himself quite blind. Ophthalmoscopic examination showed slight retinal oedema; the arteries were a little reduced in size, the macula standing out as a cherry red spot. There was no recovery of sight. The discs became atrophic. The author discusses the action of filix mas, contrasting it with that of quinine; he thinks that the blindness cannot be due to anaemia from constriction of the arteries but that the drug must have an elective action on the fibres of the optic nerve. The author points to the necessity of removing the drug from the bowels soon after ingestion by appropriate purgatives.

HaRold Grimsdale.

(4) Contino (Palermo):-The visibility of the hyaloid canal. (La questione della visibilita del canale ialoideo). Ann. di Ottal., January, 1939.

(4) Contino gives an account of all the forms which the hyaloid canal may take, and discusses their origin. He gives an account of two cases which have come under his observation; he shows how the canal may become visible as the result of vitreous haemorrhage and may be lost again when the blood is absorbed.

HAROLD GRI MSDALE. 
(5) Tita (Catania).-Primary glioma (spongioblastoma) of the optic nerve with "meningiomatosis" of the sheaths. (Glioma, spongioblastoma mono-polare astrocitario, primitivo del nervo ottico, con "meningiomatosi" della guaine). Boll. d'Ocul., April, 1939.

(5) The patient to whom this report refers, was a small boy brought by his mother who had noted that his divergent and prominent left eye had lost all sight. There was nothing to be felt in the orbit. Movement of the eye was possible in all directions but was limited in all. There was complete atrophy of the papilla. There was no sign of involvement of any accessory sinus. The growth seemed to be in the orbit only; by Calderaro's method the soft parts making the anterior wall of the orbit, including the eye, were turned to one side and the contents of the orbit removed. The cavity was almost filled by a mass, the coats of which were ruptured by the finger in isolating it. It was clear that the optic nerve was the source of the mass; no trace of the nerve could be found except for a few millimetres where it was attached to the eye. The wound healed well; there was a trophic keratitis after the operation, but this cleared. Examination of the growth showed that it was primary spongioblastoma of the nerve. The nature of the changes in the sheath of the nerve is not easy to explain. After considerable discussion, Tita leaves the matter still unsolved. The paper is well illustrated with micro-photographs of the tumour.

\section{HAROLD GRIMSDALE.}

(6) Haster, W. T. (Everett, Washington).-Standardization of the preparation of eye-drops. Amer. Jl. Ophthal., Vol. XXII, p. $423,1939$.

(6) Haster comments on the contamination of preparations of eye-drops used in hospital and private practice. It seems that after the drops have been used once or twice bacterial cultures are positive, and later molds and fungi may occur, particularly is this so in damp climates.

$\mathrm{He}$ recommends the use of a Nipagin-Nipasol combination as a germicide and preservative. These substances are the ester derivatives of benzoic acid, Nipagin-m is p-oxybenzoic acid-methyl ester and Nipasol-m is p-oxybenzoic acid-propyl ester. The combination is non-poisonous and non-toxic to man, it is harmless as a pharmaceutical preservative, two to four times less so than phenol. It was found that 0.05 per cent. Nipagin-m with 0.05 per cent. Nipasol-m in solution killed B.coli and staphylococcus pyocyaneus in six days, and destroyed common moulds, yeasts, fungi and Gram-positive and Gram-negative bacilli.

The author states that Eschenbrenner found it possible to kill resistant spores with a 0.1 per cent. Nipagin-Nipasol solution in 15 
minutes by boiling at $100^{\circ} \mathrm{C}$. while without using this estercombination it took four hours to effect the same result.

The author recommends the following dilution for the sterilization of eye solutions:-65 parts Nipagin-m plus 35 parts Nipasol-m. This solution is non-toxic, non-irritating and chemically neutral, it kills staphylococcus aureus in 24 hours and prevents the growth of tungi.

Details are given for the preparation of standard eye-drops, the preparation of an acid buffer solution and an alkaline buffer solution, and there is a table showing the amount of these to be added to the various drugs used in ophthalmic practice.

\section{H. B. Stallard.}

(7) Greene, L. S. and Perry, N. W. (Washington).-Erythema nodosum with nodules in the conjunctivae. Amer. Jl. Ophthal., Vol. XXII, p. 389, 1939.

(7) Greene and Perry describe the case of a woman, aged 54 years, who developed areas of hyperaemia and nodules in the bulbar conjunctiva of each eye over the insertions of the four recti muscles. These ocular changes appeared simultaneously with the characteristic cutaneous lesions of erythema nodosum affecting the extensor aspects of the forearms and legs, and also with the onset of malaise raised temperature and arthralgia.

The conjunctival lesions were triangular in shape with the base towards the limbus and were localized to the bulbar conjunctiva. They were raised, deep cherry-red in colour, painless and movable over the unaffected sclera. In the centre of the nodules were two to four nodules about the size of a pin's head. A slit-lamp examination of these lesions showed them to consist of a superficial wide meshwork of dark red vessels, a network of small vessels surrounded each nodule, the nodule itself laying in sanguineous fluid. Some of the nodules stained slightly with fluorescein.

Complete recovery occurred eight weeks from the onset of the illness. Treatment consisted of sodium salicylate grs. 45 daily, rest in bed, and hot gargles for the pharyngitis.

The few cases reported in the literature are briefly reviewed.

\section{H. B. Stallard.}

(8) Persichetti (Rome).-The haemoclasic reaction in luetics with ocular signs. (La reazione emoclasica nei luetici con manifestazioni oculari). Boll. d'Ocul., March, 1939.

(8) It is well known that when proteins of various kinds, or vaccines are introduced to healthy subjects, there follows almost constantly, a leucocytosis; on the other hand if a subject of certain diseases be injected with the appropriate vaccine or with the 
curative drug, there follows immediately a fall in the number of leucocytes; this fall takes place at once and is at height about half to three quarters of an hour after the injection. There follows in a short time a rise to the preceding state.

Persichetti has examined the reaction in a number of cases in which there was a certain history of syphilis; in these, 21 out of 30 were positive showing a reduction of the number of leucocytes by at least $8 \mathrm{co}$. Of the cases which did not show the reaction, some were under treatment; this would very probably interfere with the change in the leucocyte count.

Two other series were examined; one showing a negative Wassermann reaction, was considered to be syphilitic; the other was not infected. Of the first who numbered 25, eight were positive; of the normal, none. Comparing the reaction with the Wassermann, it seems clear that in some cases in which the W. R. is negative, this reaction is positive, but it does not seem to be superior to the W. R. in all cases; it would seem at least to be a useful adjuvant where there is doubt.

HaRold GRIMSDale.

(9) Borsotti, (Pavia).-A case of paralysis of the third nerve, with disturbance of swallowing and speaking. (Considerazioni su un caso di paralisi parcellare del III paio con disturbi della deglutizi ne e fonazione). Riv. Oto. Neuro. Oftal., January, 1939.

(9) The difficulty in the exact diagnosis of nervous lesions is well known. Borsotti publishes a case which presented considerable doubt. The man, aged 44 years, had noticed for six weeks a little disturbance in vision which disappeared on closing one or other eye. Recently he had noticed deviation of the left eye outwards with constant double vision, and some drooping of the lid; at the same time he had difficulty in swallowing and his voice had become nasal: He denied lues, and the examination of the blood and cerebrospinal fluid was negative. He was a heavy drinker. The right eye was normal throughout; the left showed paralysis of the internal rectis, and levator palpebrae with paresis of the rectus superior. Further examination showed paresis of the soft plate and of the constrictors of the pharynx; also loss of power over the vocal cords. Treatment by bismuth injections (salbiol) was soon followed by improvement, and this was increased by the additional injection of iodide intravenously. The diagnosis at first was disseminated sclerosis; the rapid improvement was not unlike the course of this disease; later a possible luetic cerebral lesion, or a toxic neuritis were considered as more probable; it must be remembered that the man was a heavy drinker.

HAROLD GRIMSDALE. 
(10) Nicolato (Pavia).--Some results of reconstruction of the lids after gross losses. (Considerazione su alcuni risultati di ricostruzione delle palpebre a seguito di gravi traumi). Ann. di Ottal., February, 1939.

(10) It is not infrequent for patients to suffer a grave deformity of the lids to remain uncorrected, because they fear an operation or some other reason. Nicolato holds that it is the surgeon's duty to urge some operation, not only because the condition may lead to damage to the eye, but also because the unsightly appearance is distressful to the friends.

The choice of operation is not always easy and no one method is applicable to all defects. The author prefers, where possible, to use Dieffenbach's or Fricke's method, so as to obtain the skin to form the new lid from some near region; but on occasion he uses Gillies's plan of tubular grafts taken from a distance. He lays stress on the necessity of making the flaps large enough, cutting them with curved outlines to preserve as far as possible their blood supply if the base must be twisted. He advises that all bleeding be carefully stopped by pressure or torsion of the vessels; ligatures must be avoided. Sutures must be put in carefully; those needed to fix the flap in position should be stronger than those which bring the edges together. Tarsorrhaphy is needed in most cases and should remain undivided for two months.

A number of photographs are given showing the excellent results obtained, and in some cases the various stages of the procedure.

HAROLD GRIMSDALE.

(11) Schumacher, G. (Basle).-Monocular and binocular threshold values in dark adaptation of the eye in day vision and night vision. (Ueber des Verhalten der monokularen und binokularen Reizschwelle während der Dunkeladaptation des Tagesund Dammerungsapparates). Acta Ophthal., Vol. XV, p. 1, 1939.

(11) Schumacher reviews the literature on the subject of binocular summation on which discordant results are reported except that there is agreement that in foveal day vision there is no binocular summation. On an exhaustive re-examination of the whole subject he concludes that (1) the apparatus for scotopic vision shows binocular summation. (2) There is no such effect in the photopic apparatus. (3) Summation in the scotopic eye is less marked at the beginning of dark adaption than after 45 minutes, when the monocular threshold value is practically double that of the two eyes together. (4) There is an inter-relationship between the scotopic and the photopic apparatus, influencing the reactions of the photopic apparatus.

ARNOLD SORSBY. 
(12) Möller, H. U. (Copenhagen).-Symptoms simulating glaucoma in a case of chordoma. (Symptomes, simulant de glaucome, dans un chordome du clivus blumenbachii). Acta Ophthal., Vol. XVII, p. 20, 1939.

(12) Möller recalls the work done on pseudo-glaucomatous cupping and emphasises Traquair's view that an arcuate scotoma by itself is not pathognomonic of glaucoma. He describes in detail the clinical and histological findings in a case showing cupping and optic atrophy suggestive of glaucoma, arcuate scotoma, but no increase of intra-ocular tension. The condition was ultimately established as due to a pituitary lesion.

\section{ARNOLD SORSBY.}

(13) Karbowski, M. (Warsaw).-Iontophoresis in ophthalmology. Ophthalmologica, Vol. XCVII, p. 166, 1939.

(13) In a detailed discussion on the methods and scope of iontophoresis, Karbowski emphasises the greater therapeutic effect of ionised substances, especially the ions of calcium, potassium, adrenaline, atropine and pilocarpine. He stresses in particular the value of adrenaline ionisation which surpasses the effect of subconjunctival injection.

\section{ARNOLD SORSBY.}

(14) Igersheimer, J. (Istanbul).-Can glaucoma influence transudation from retinal vessels? (Ist ein Glaukom imstande, die Transudation aus den Netzhautgefässen zu beeinflussen?). Ophthalmologica, Vol. XCVII, p. 146, 1939.

(14) Igersheimer gives the clinical and post-mortem findings in a patient, aged 42 years, who had shown severe vascular hypertension with uraemia. During the last eighteen months of life glaucomatous excavation was present, but there was no retinal change. He discusses the question of whether the absence of transudates is to be explained by the co-incident presence of the glaucoma.

ARNOLD SORSBY.

(15) Redslob, M. E. (Strasbourg).-The teeth and optic nerve. (Les dents et le nerf optique). Ophthalmologica, Vol. XCVII, p. 133, 1939.

(15) Redslob reports a case of retrobulbar neuritis in which both nerves were attacked within an interval of two years. On each occasion recovery took place after extraction of an infected tooth, improvement setting in within a few hours and full vision being restored within four or five days. He accepts this as conclusive proof of causality and discusses the possible mechanism. $\mathrm{He}$ inclines to the probability of angiospasm in the retrobulbar part of the nerve set up by reflex irritation, or alternatively to a local allergic reaction.

ARNOLD SORSBY. 